\title{
The combined effects of garlic oil and fish oil on the hepatic antioxidant and drug-metabolizing enzymes of rats
}

\author{
Haw-Wen Chen ${ }^{1}$, Chia-Wen Tsai ${ }^{1}$, Jaw-Ji Yang ${ }^{2}$, Cheng-Tze Liu ${ }^{1}$, Wei-Wen Kuo ${ }^{3}$ and \\ Chong-Kuei $\mathrm{Lii}^{1} *$ \\ ${ }^{1}$ Department of Nutrition, ${ }^{2}$ School of Dentistry and ${ }^{3}$ Institute of Biochemistry, Chung Shan Medical University, \\ Taichung 402, Taiwan
}

(Received 8 November 2001 - Revised 30 August 2002 - Accepted 22 September 2002)

\begin{abstract}
This present study was designed to investigate the combined modulatory effect of garlic oil (GO) and fish oil (FO) on the antioxidant and drug metabolism systems. Rats were fed either a low-maize oil (MO) diet $(50 \mathrm{~g} \mathrm{MO} / \mathrm{kg})$, high-MO diet $(235 \mathrm{~g} \mathrm{MO} / \mathrm{kg})$ or high-FO diet $(205 \mathrm{~g} \mathrm{FO}+30 \mathrm{~g} \mathrm{MO} / \mathrm{kg})$ and received different doses of GO $(0-200 \mathrm{mg} / \mathrm{kg}$ body weight) three times per week for 6 weeks. Fatty acid analysis showed that $20: 5 n-3$ and $22: 6 n-3$ were incorporated into serum lipid at the expense of $18: 2 n-6$ and $20: 4 n-6$ in rats fed the high-FO diet. GO dose-dependently increased hepatic glutathione $S$-transferase (GST), glutathione reductase, superoxide dismutase (SOD) and ethoxyresorufin $O$-deethylase (EROD) activities, but decreased glutathione peroxidase and $N$-nitrosodimethylamine demethylase (NDMAD) activities $(P<0.05)$. With the exception of glutathione peroxidase, the activities of glutathione reductase, SOD, GST, EROD and NDMAD were modulated by the dietary fat. The high-FO group had greater SOD and EROD activity than either MO-fed group; it also had greater NDMAD activity than the low-MO group $(P<0 \cdot 05)$. GST activity was higher in rats fed high-FO or high-MO diets than rats fed the low-MO diet. Change in erythromycin demethylase activity, however, was not caused by either dietary fat or GO. Immunoblot assay showed that GO dose-dependently enhanced the protein level of the Ya, Yb1, Yc isoenzymes of GST and cytochrome P450 (CYP) 1A1 and 3A1, but GO suppressed CYP2E1 expression. Regardless of the dosage of GO, the high-FO diet increased CYP1A1, CYP3A1 and CYP2E1 levels compared with the high- and low-MO diets. Accompanying the changes observed in immunoblots, CYP1A1 and CYP3A1 mRNA levels were increased by GO in a dose-dependent manner and also increased additively in combination with FO feeding. These present results indicate that co-administration of GO and FO modulates the antioxidant and drug-metabolizing capacity of animals and that the effect of GO and FO on drug-metabolizing enzymes is additive.
\end{abstract}

Fish oil: Garlic oil: Antioxidant enzymes: Cytochrome P450

Drug metabolism systems are composed of phase I and II enzymes. Phase I enzymes, mainly cytochrome P450 (CYP), detoxify a variety of endogenous and exogenous chemicals and activate many carcinogens (Guengerich, 1991). Phase II enzyme systems catalyse the conjugation of phase I metabolites to various water-soluble molecules, such as glutathione (GSH) or glucuronic acid, which accelerates metabolite excretion rate. Glutathione $S$-transferase (GST) is one of the most important phase II enzymes. GST not only conjugates GSH to various electrophilic compounds, but also acts as a Se-independent GSH peroxidase. Oxidative stress of endogenous and exogenous origins is known to be involved in cancer formation and in many of the diseases associated with ageing, such as cardiovascular disease, stroke, arthritis and cataract (Cross et al. 1987). An effective defence mechanism is, thus, important to the health of animals and man (Machlin \& Bendich, 1987). The inherent antioxidant defence system is composed of antioxidants, such as vitamin $\mathrm{E}$ and vitamin $\mathrm{C}$, and antioxidant enzymes, such as GSH peroxidase, catalase and superoxide dismutase (SOD). SOD is involved in quenching the superoxide anion and in the formation of $\mathrm{H}_{2} \mathrm{O}_{2}$, and $\mathrm{H}_{2} \mathrm{O}_{2}$ is then decomposed to $\mathrm{H}_{2} \mathrm{O}$ by catalase and $\mathrm{GSH}$ peroxidase. Because of the

Abbreviations: CYP, cytochrome P450; EROD, ethoxyresorufin $O$-deethylase; GO, garlic oil; GSH, glutathione; GSSG, glutathione disulfide; GST, glutathione $S$-transferase; MO, maize oil; FO, fish oil; NDMAD, $N$-nitrosodimethylamine demethylase; SOD, superoxide dismutase; TBARS, thiobarbituric acid-reactive substances.

* Corresponding author: Dr Chong-Kuei Lii, fax +886 4 4739030, email cklii@csmu.edu.tw 
important role of antioxidant and drug-metabolizing enzymes against oxidative stress and chemical-induced toxicity, any factors modulating the activity or expression of these enzymes may lead to altered susceptibility of animals to environmental injury.

In recent years, there has been an increasing emphasis on foods and food components in disease prevention. Garlic and its related compounds have attracted a great deal of attention. The significant effects of garlic on disease prevention are in the fields of cardiovascular disease and cancer (Agarwal, 1996; Rahman, 2001). Recently, Fleischhauer \& Arab (2001) have summarized the epidemiological evidence and indicated that the consumption of garlic was inversely correlated with the incidence of stomach and colorectal cancer; however, the effect of garlic on lung, breast and prostate cancer is inconsistent and needs further studies. Among various garlic components, the organo-S compounds are considered the most potent in chemoprevention of cancer, and their preventive capabilities are related to their modulation of drug-metabolizing enzymes involved in the activation or detoxification of carcinogens (Yang et al. 1994). In an animal study, four garlic-derived organo-S compunds, i.e. allyl methyl trisulfide, allyl methyl disulfide, diallyl trisulfide and diallyl sulfide, were found to inhibit benzo(a)pyrene-induced forestomach neoplasia and were accompanied by an increase in GST activity in the forestomach (Sparnins et al. 1988). Garlic components are also effective in modulating GSH peroxidase, GSH reductase and SOD activities (Iqbal \& Athar, 1998; Sheen et al. 1999) and in inhibiting lipoprotein oxidation (Phelps \& Harris, 1993).

Interest in $n-3$ fatty acids arose 30 years ago when studies showed that intake of $n-3$ polyunsaturated fatty acids in marine fish oils (FO) was associated with a low incidence of cardiovascular disease in Greenland Eskimos (Dyerberg et al. 1975; Bang et al. 1980). In addition to their well-known cholesterol- and triacylglycerol-lowering effects, the following effects of $n-3$ polyunsaturated fatty acids are recognized to be associated with their antiatherosclerotic actions: modulation of thromboxane $\mathrm{A}_{2}$ and prostacyclin production (Goodnight et al. 1982); inhibition of monocyte migration into the plaque, reduction in cytokine and interleukin $1 \alpha$ production; stimulation of endothelial NO production (Shimokawa \& Vanhoutte, 1989); reduction in platelet-derived growth factor (Fox \& DiCorleto, 1988). However, there is growing concern that high content of polyunsaturated fatty acids increases lipid peroxidation and free-radical production and thus increases the risk of carcinogenesis (Fang et al. 1996). To compensate for the damage of oxidative stress, $n-3$ polyunsaturated fatty acids have also been shown to enhance GSH peroxidase, GSH reductase and SOD activities in rat livers (RuizGutiérrez et al. 1999).

FO and garlic-derived products are popular health supplements. However, few studies have investigated how garlic components interact with dietary lipids to modulate the physiological and biological actions. In a recent study, we have reported that co-administration of garlic oil (GO) and FO additively increased both CYP2B1 and the placental form of GST protein and mRNA expression (Chen et al. 2001). This finding implies the possible cross-reaction of these two health supplements in their physiological activities. This has also been demonstrated by the anti-hyperlipidaemic and anti-hypercholesterolaemic effect of co-administration of GO and FO (Alder \& Holub, 1997; Morcos, 1997). Based on this evidence, it is of interest to examine the effects of FO on the antioxidant and drug-metabolizing system, and whether these effects are modulated by garlic components.

In this present study, male Sprague-Dawley rats were fed three diets varying in the amount and type of fat, and given oral administrations of $0-200 \mathrm{mg} \mathrm{GO} / \mathrm{kg}$ body weight three times per week, to investigate the individual and combined effects of dietary lipid and GO on antioxidant and drugmetabolizing enzymes.

\section{Materials and methods}

\section{Materials}

GO was prepared with a steam distillation technique, as previously described (Chen et al. 2001). 2,4-Chloro-dinitrobenzene, GSH, oxidized GSH (GSH disulfide, GSSG), ethoxyresorufin, erythromycin, $N$-nitrosodimethylamine and other biochemical reagents were purchased from Sigma Chemical (St Louis, MO, USA). Antibodies against GST Ya, Yb1 and Yc isoenzymes were purchased from Biotrin (Dublin, Republic of Ireland). Anti-CYP1A1, CYP2E1 and CYP3A1 polyclonal antibodies were purchased from Oxford Biomedical Research (Oxford, MI, USA).

\section{Animals and treatments}

Male Sprague-Dawley rats (4 weeks old) were purchased from the National Animal Breeding and Research Centre (Taipei, Taiwan). After 1 week of acclimatization, rats were randomly assigned to each experimental group by weight and housed in plastic cages with a $12 \mathrm{~h}$ lightdark cycle. Rats were fed a diet containing $50 \mathrm{~g}$ maize oil (MO)/kg (low MO), $235 \mathrm{~g} \mathrm{MO} / \mathrm{kg}$ (high MO) or $205 \mathrm{~g}$ $\mathrm{FO}+30 \mathrm{~g} \mathrm{MO} / \mathrm{kg}$ (high FO) (Table 1) as described by

Table 1. The composition of experimental diets

\begin{tabular}{lccc}
\hline Ingredients $^{*}(\mathrm{~g} / \mathrm{kg})$ & Low MO & High MO & High FO \\
\hline Casein & 20.0 & 23.5 & 23.5 \\
Sucrose & 49.5 & 25.63 & 25.63 \\
Maize starch & 15.0 & 15.0 & 15.0 \\
MO† & 5.0 & 23.5 & 3.0 \\
FO† & - & - & 20.5 \\
Cellulose & 5.0 & 5.9 & 5.9 \\
AIN76 mineral mix & 3.5 & 4.11 & 4.11 \\
AlN76 vitamin mix & 1.0 & 1.18 & 1.18 \\
Methionine & 0.3 & 0.35 & 0.35 \\
Choline bitartrate & 0.2 & 0.24 & 0.24 \\
Cholesterol & 0.5 & 0.59 & 0.59 \\
\hline
\end{tabular}

MO, maize oil; FO, fish oil.

${ }^{*}$ All diet ingredients, except FO, were purchased from Harlan Teklad (Madison, MI, USA)

† Vitamin E content of the FO and MO was 490 and $170 \mathrm{mg} \alpha$-tocopherol equivalents/kg respectively.

‡FO was purchased from Tama Biochemical Co. (Tokyo, Japan). 
Reddy \& Sugie (1988) for 6 weeks. The composition of all experimental diets was adjusted so that rats in all dietary groups would receive the same dosage of vitamins, minerals and fibre (Reddy \& Sugie, 1988). During the entire experiment, rats were administered $0,30,80$ and $200 \mathrm{mg}$ $\mathrm{GO} / \mathrm{kg}$ body weight (MO as a vehicle) by oral intubation three times per week. Rats were allowed free access to water and diet, and treated in compliance with National Research Council (1985) guidelines. Body weight was measured weekly.

After 6 weeks, rats were fasted overnight and killed with $\mathrm{CO}_{2}$. The livers, spleens, hearts and jugular lymph nodes were removed and weighed immediately. Fresh livers were used for microsome and cytosol preparations or quickly freeze-clamped in liquid $\mathrm{N}_{2}$ and stored at $-80^{\circ} \mathrm{C}$. For cytosol and microsome preparations, livers

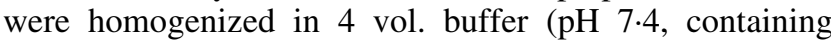
$10 \mathrm{~mm}$-potassium phosphate and $\mathrm{KCl}(11.5 \mathrm{~g} / \mathrm{l}))$, and centrifuged at $10000 \mathrm{~g}$ for $30 \mathrm{~min}$ at $4^{\circ} \mathrm{C}$. The resultant supernatant fraction was further ultracentrifuged at $105000 \mathrm{~g}$ for $1 \mathrm{~h}$, and the final cytosolic and microsomal fractions were stored at $-80^{\circ} \mathrm{C}$ until analysis.

\section{Serum fatty acid and liver fat analysis}

Serum fatty acid analysis was performed by the method described by Lepage \& Roy (1986). Fatty-acid methyl esters were quantified by GC (Hitachi G3000; Hitachi, Tokyo, Japan). A $30 \mathrm{~m}$ fused silica column with an internal diameter of $0.25 \mathrm{~mm}$ (Supelco, Bellefonte, PA, USA) was used. The column was wall-coated with $0 \cdot 2 \mathrm{~mm} \mathrm{SP-2330}$ (Supelco). Peaks were identified by comparing the retention times with those of authentic fatty-acid methyl ester standards (Sigma). Peak areas of each individual fatty acid were determined and the percentages calculated on the basis of total peak areas of all detectable fatty acids. The total lipid content of rat livers was determined as described by Folch et al. (1957).

\section{Enzyme activity assays}

Hepatic GST activity was assayed by the method of Habig et al. (1974), with 2,4-choloro-dinitrobenzene as the substrate. GSH peroxidase activity was determined spectrophotometrically with a coupled procedure using $\mathrm{H}_{2} \mathrm{O}_{2}$ as the substrate (Lawrence \& Burk, 1976). GSH reductase activity was measured by the method of Bellomo et al. (1987). SOD activity was determined with the Randox SOD kit according to the manufacturer's instructions (Randox Laboratories Ltd, Antrim, UK) and was calculated by the degree of inhibition of 2-(4-iodophenyl)-3-(4-nitrophenol)-5-phenyltetrazolium chloride reaction with superoxide anion generated by xanthine-xanthine oxidase. One unit SOD activity is defined as the amount of enzyme required to inhibit the rate of 2-(4-iodophenyl)-3(4-nitrophenol)-5-phenyltetrazolium chloride oxidation by $50 \%$. $N$-nitrosodimethylamine demethylase (NDMAD) and erythromycin demethylase activities were determined by the method of Nash (1953). Briefly, $0.35 \mathrm{ml}$ microsomal protein $(1 \mathrm{mg} / \mathrm{ml})$ was mixed with $0.05 \mathrm{ml} 10 \mathrm{mM}-\mathrm{MgCl}_{2}$ and either $0.05 \mathrm{ml} \quad 50 \mathrm{~mm}-N$-nitrodimethylamine or $0.05 \mathrm{ml} 10 \mathrm{mM}$-erythromycin, then $0.05 \mathrm{ml} 10 \mathrm{mM}-$ NADPH was added to start the reaction. The reaction mixture was incubated at $37^{\circ} \mathrm{C}$ for $10 \mathrm{~min}$. The reaction was stopped by adding $0.1 \mathrm{ml} \mathrm{ZnSO}_{4}(50 \mathrm{~g} / \mathrm{l})$ and $0.1 \mathrm{ml}$ saturated $\mathrm{Ba}(\mathrm{OH})_{2}$ solutions. Ethoxyresorufin $O$-deethylase (EROD) activity was measured with a fluorescence spectrophotometer (F4500; Hitachi) as previously described (Poul \& Fouts, 1980).

\section{Glutathione S-transferase, $\alpha$-tocopherol and lipid peroxidation assays}

Fresh liver tissues were used to measure GSH redox status and $\alpha$-tocopherol levels. Hepatic GSH and GSSG concentrations were determined by HPLC as described by Reed et al. (1980). $\alpha$-Tocopherol was measured by means of a modification of the procedure previously described (Catignani \& Bieri, 1983). Lipid peroxidation was determined by measuring thiobarbituric acid-reactive substances (TBARS) as described by Fraga et al. (1988). Fresh livers were homogenized in 14 vol. $10 \mathrm{~mm}$-potassium phosphate buffer, $\mathrm{pH} 7 \cdot 4$. Cell homogenates were then used for determination of the endogenous TBARS or incubated with an exogenous oxidant, i.e. $50 \mu \mathrm{M}-\mathrm{FeSO}_{4}$, at $37^{\circ} \mathrm{C}$ for $30 \mathrm{~min}$ to induce lipid peroxidation. Butylated hydroxytoluene was added to terminate lipid peroxidation. The fluorescence of samples was detected at an excitation wavelength of $515 \mathrm{~nm}$ and an emission wavelength of $555 \mathrm{~nm}$ in a F4500 fluorescence spectrophotometer (Hitachi). 1,1,3,3-Tetramethoxypropane was used as a malondialdehyde precursor and a TBARS standard.

\section{Immunoblot assay}

Protein levels in liver cytosols and microsomes were determined by the method of Lowry et al. (1951). Equal amounts of liver cytosolic and microsomal protein of each animal in each group were pooled and then were subjected to SDS-polyacrylamide gel electrophoresis (Laemmli, 1970). Following electrophoresis, proteins separated on gels were transferred to polyvinylidiene difluoride membranes. The membranes were incubated with non-fat dried milk $(50 \mathrm{~g} / \mathrm{l}$ in $15 \mathrm{~mm}$-Tris $-150 \mathrm{mM}-\mathrm{NaCl}$ buffer, $\mathrm{pH} 7.4)$ at $4^{\circ} \mathrm{C}$ overnight, to block non-specific binding. Then, membranes were incubated with CYP1A1 or CYP2E1 or CYP3A1 antibody at $37^{\circ} \mathrm{C}$ for $1 \mathrm{~h}$ followed by peroxidase-labelled goat anti-rabbit immunoglobulin G. For GST isoenzyme detection, membranes were coincubated with GST $\mathrm{Ya}, \mathrm{Yb} 1$ and $\mathrm{Yc}$ antibodies. $\mathrm{H}_{2} \mathrm{O}_{2}$ and tetrahydrochloride diaminbenzidine were used for colour development.

\section{Northern blot analysis}

Total RNA was extracted by homogenizing $50 \mathrm{mg}$ fresh liver tissues in $1 \mathrm{ml}$ Trizol reagent (Life Technologies Inc., Grand Island, NY, USA) using a Potter-Elvehjem homogenizer (Glas-Col Co., Texxe Haute, IN, USA). For Northern blot analysis, two pairs of oligonucleotide primers were designed based on the published sequences of 
CYP1A1 (forward 5'-CTGCCTTGGATTCTGGGTGGTT$3^{\prime}$, backward 5'-CAAAGGATGAATGTCGGA-AGGT-3') and CYP3A1 (forward 5'-TTGCCATCACGGACACAGAAAT- $3^{\prime}$, backward 5'-ATGCTGC-CCTTGTTCTCCTTGC- $\left.3^{\prime}\right)$. Reverse transcription-polymerase chain reaction was performed as previously described (Chen et al. 2001). The DNA fragment of CYP1A1 and CYP3A1 were labelled with $\alpha$-deoxy-cytidine $5^{\prime}-\left[{ }^{32} \mathrm{P}\right]$ triphosphate and used as probes for Northern blot analysis. From each sample, $20 \mu \mathrm{g}$ RNA was electrophoretically separated by agarose $(10 \mathrm{~g} / \mathrm{l})$ gel containing formaldehyde $(60 \mathrm{ml} / \mathrm{l})$ and transferred to HyBond membrane (Amersham Pharmacia Biotech, Arlington Heights, IL, USA). For hybridization with cDNA, the membrane was prehybridized for $2 \mathrm{~h}$ at $42^{\circ} \mathrm{C}$ in a solution containing Denhardt's reagent (g/l: Ficoll 20, polyvinylpyrolidone 20, bovine serum albumin 20), sodium chloride-sodium phosphateEDTA buffer $\left(750 \mathrm{~mm}-\mathrm{NaCl}, 50 \mathrm{~mm}-\mathrm{NaH}_{2} \mathrm{PO}_{4}, 5 \mathrm{~mm}-\right.$ EDTA), SDS $(20 \mathrm{~g} / \mathrm{l})$, formamide $(500 \mathrm{~g} / \mathrm{l})$, and $100 \mu \mathrm{g}$ single-strand sheared salmon sperm DNA $/ \mathrm{ml}$. The membrane was then hybridized in the same solution with ${ }^{32} \mathrm{P}$-labelled CYP1A1 cDNA probe at $42^{\circ} \mathrm{C}$ overnight. After washing, autoradiography was performed by exposing the membrane to Kodak SuperRx x-ray film (Rochester, NY, USA) at $-80^{\circ} \mathrm{C}$ with an intensifying screen. For rehybridization with CYP3A1 cDNA probe, the membrane was deprobed by washing twice with boiling SDS $(1 \mathrm{~g} / \mathrm{l})$. The bands on the $\mathrm{x}$-ray film were measured with an AlphaImager ${ }^{\mathrm{TM}}$ 2000 (Alpha Innotech Co., San Leandro, CA, USA).

\section{Statistical analysis}

Data were analysed by means of ANOVA and Tukey's test was used to test the significance of GO treatments in each dietary-fat-fed group. Two-way ANOVA was used to test the effects of both dietary fat and GO and their interaction. All statistical analyses were performed with commercially available software (SAS Institute Inc., Cary, NC, USA).

\section{Results}

\section{Growth characteristics}

There was no significant difference in the body-weight gain of rats fed different dietary lipid amount and source. No effect of $\mathrm{GO}$ administration on the growth of rats was found either. The average food intakes in rats fed the low-MO, high-MO or high-FO diets were 20.8 (SD 3.2), $18 \cdot 1$ (SD 2.7) and 16.7 (SD 2.9) g/d respectively, and there was no difference among GO treatments in each dietary group (results not shown). Different dietary lipid amount significantly affected the relative liver weight of rats $(P<0.05)$ (Table 2$)$. Rats fed the high-fat diet, either high-MO or high-FO, had significantly greater relative liver weight than rats fed a low-MO diet $(P<0.05)$; however, there was no significant difference between rats fed either high-fat diet. Different doses of GO had no effect on the relative liver weight of rats. Relative heart and kidney weights were not changed by dietary lipid and GO. Relative spleen weight of rats was not affected by dietary lipid amount and source; however, it was significantly changed by GO. In each dietary lipid group, GO dose-dependently increased the relative spleen weight (Table 2). Rats that received $200 \mathrm{mg} \mathrm{GO} / \mathrm{kg}$ body weight doubled the relative spleen weight as compared with rats receiving no GO. The relative weight of the jugular lymph nodes was related to the amount but not the

Table 2. Effect of garlic oil (GO) on the growth characteristics of rats receiving different types and amounts of dietary fat for 6 weeks $\dagger$

(Mean values and standard deviations for five rats per group)

\begin{tabular}{|c|c|c|c|c|c|c|c|c|c|c|c|c|c|}
\hline Diet & $\mathrm{GO}(\mathrm{mg} / \mathrm{kg}) \ddagger$ & \multicolumn{2}{|c|}{$\begin{array}{l}\text { Body-wt } \\
\text { gain }(g)\end{array}$} & \multicolumn{2}{|c|}{$\begin{array}{l}\text { Liver wt/body } \\
\text { wt (\%) }\end{array}$} & \multicolumn{2}{|c|}{$\begin{array}{c}\text { Heart wt/body } \\
\text { wt (\%) }\end{array}$} & \multicolumn{2}{|c|}{$\begin{array}{c}\text { Kidney } \\
\text { wt/body wt } \\
(\%)\end{array}$} & \multicolumn{2}{|c|}{$\begin{array}{c}\text { Spleen } \\
\text { wt/body wt } \\
(\%)\end{array}$} & \multicolumn{2}{|c|}{$\begin{array}{c}\text { Jugular lymph- } \\
\text { node wt/body } \\
\text { wt (\%) }\end{array}$} \\
\hline \multirow[t]{3}{*}{ Low MO } & 0 & 265 & 22 & 4.00 & 0.27 & 0.25 & 0.03 & 0.79 & 0.04 & $0.20^{c}$ & 0.03 & 0.037 & 0.005 \\
\hline & 30 & 248 & 30 & $4 \cdot 01$ & 0.34 & 0.27 & 0.01 & 0.79 & 0.06 & $0.21^{c}$ & 0.01 & 0.035 & 0.009 \\
\hline & 80 & 235 & 30 & $4 \cdot 13$ & 0.39 & 0.28 & 0.03 & 0.87 & 0.09 & $0.31^{c}$ & 0.07 & 0.038 & 0.005 \\
\hline \multirow[t]{4}{*}{ High MO } & 0 & 283 & 36 & $4 \cdot 29$ & 0.23 & 0.26 & 0.02 & 0.75 & 0.09 & $0.19^{c}$ & 0.01 & 0.029 & 0.003 \\
\hline & 30 & 285 & 12 & $4 \cdot 45$ & 0.36 & 0.26 & 0.01 & 0.77 & 0.09 & $0 \cdot 21^{\mathrm{c}}$ & 0.01 & 0.030 & 0.004 \\
\hline & 80 & 271 & 18 & 4.40 & 0.26 & 0.26 & 0.03 & 0.75 & 0.14 & $0.28^{\mathrm{b}}$ & 0.03 & 0.027 & 0.003 \\
\hline & 200 & 246 & 21 & $4 \cdot 48$ & 0.30 & 0.30 & 0.03 & 0.82 & 0.02 & $0.42^{\mathrm{a}}$ & 0.08 & 0.033 & 0.003 \\
\hline \multirow[t]{4}{*}{ High FO } & 0 & 286 & 42 & $4 \cdot 36$ & 0.36 & 0.28 & 0.01 & 0.83 & 0.06 & $0.23^{c}$ & 0.03 & 0.026 & 0.004 \\
\hline & 30 & 269 & 32 & 4.47 & 0.27 & 0.27 & 0.01 & 0.81 & 0.05 & $0.23^{c}$ & 0.02 & 0.030 & 0.006 \\
\hline & 80 & 252 & 39 & $4 \cdot 45$ & 0.40 & 0.28 & 0.04 & 0.82 & 0.06 & $0.33^{b}$ & 0.04 & 0.034 & 0.007 \\
\hline & 200 & 254 & 57 & $4 \cdot 40$ & 0.55 & 0.26 & 0.03 & 0.83 & 0.13 & $0.43^{\mathrm{a}}$ & 0.07 & 0.034 & 0.009 \\
\hline \multirow{2}{*}{\multicolumn{2}{|c|}{$\begin{array}{l}\text { Dietary fat } \\
\text { GO }\end{array}$}} & \multicolumn{2}{|c|}{ NS } & \multicolumn{2}{|c|}{$0.004^{*}$} & \multicolumn{2}{|c|}{ NS } & \multicolumn{2}{|c|}{ NS } & \multicolumn{2}{|c|}{ NS } & \multicolumn{2}{|c|}{$0.0002^{\star *}$} \\
\hline & & \multicolumn{2}{|c|}{ NS } & \multicolumn{2}{|c|}{ NS } & \multicolumn{2}{|c|}{ NS } & \multicolumn{2}{|c|}{ NS } & \multicolumn{2}{|c|}{0.0001} & \multicolumn{2}{|c|}{ NS } \\
\hline \multicolumn{2}{|l|}{ Dietary fat $\times$ GO } & \multicolumn{2}{|c|}{ NS } & \multicolumn{2}{|c|}{ NS } & \multicolumn{2}{|c|}{ NS } & \multicolumn{2}{|c|}{ NS } & \multicolumn{2}{|c|}{ NS } & \multicolumn{2}{|c|}{ NS } \\
\hline
\end{tabular}

wt, weight; MO, maize oil; FO fish oil.

a,b,c Mean values within a column and within a dietary group with unlike superscript letters were significantly different: $P<0.05$

Values for high-MO and high-FO diets were significantly greater than for the low-MO diet (Tukey's test): ${ }^{*} P<0.05$.

Values for high-MO and high-FO diets were significantly less than for low-MO diet: ${ }^{\star \star} P<0.01$.

†For details of diets and procedures, see Table 1 and p. 190.

$\ddagger \mathrm{GO}$ was given by oral intubation three times per week. 
source of dietary lipid. Rats fed the high-MO or high-FO diet had significantly lower relative lymph-node weight than rats fed a low-MO diet $(P<0 \cdot 01)$; however, there was no significant difference between rats fed the highfat diets. In each diet group, different doses of GO had no effect on the relative jugular lymph node weight of rats.

\section{Serum fatty acids and hepatic lipid content}

Dietary lipid amount and source had no significant effect on serum 14:0 and 18:0 (Table 3). Rats fed a low-MO diet had greater serum 16:0 than rats fed a high-MO diet $(P<0 \cdot 01)$. Rats fed a low-MO diet had greater serum $18: 1 n-9$ than rats fed the high-MO or high-FO diet $(P<0 \cdot 01)$. Serum $18: 2 n-6$ and $20: 4 n-6$ were significantly greater in rats fed the MO diets than rats fed FO $(P<0.001)$, and they were significantly greater in rats fed a high-MO diet than rats fed a low-MO diet $(P<0.05)$. Serum $20: 5 n-3$ and $22: 6 n-3$ were significantly higher in rats fed the high-FO diet than rats fed the low-MO or high-MO diet $(P<0 \cdot 001)$.

Total lipid content in rat livers was affected by the amount and source of dietary fat (Fig. 1). Rats fed the high-MO diet had a significantly greater lipid level than those fed the low-MO diet $(P<0 \cdot 001)$. Rats fed the highFO diet, which had the same amount of dietary fat as high-MO diet, had a lipid level similar to those fed the low-MO diet and was significantly lower than for those fed the high-MO diet $(P<0 \cdot 001)$. Different dosage of GO had no effect on the lipid content in rat liver tissues.

\section{Antioxidant status}

Dietary lipid source and amount had no effect on hepatic GSH peroxidase activity. Instead, GO significantly decreased GSH peroxidase activity (Table 4). In each dietary group, rats administered $200 \mathrm{mg} \mathrm{GO} / \mathrm{kg}$ body weight had the lowest enzyme activity, and rats that received $0 \mathrm{mg} \mathrm{GO} / \mathrm{kg}$ body weight had the greatest. Regardless of dietary lipid, GO caused a dose-dependent increase in hepatic GSH reductase activity. Moreover, the activity of $\mathrm{GSH}$ reductase was greater in rats fed a high-FO or lowMO diet than rats fed a high-MO diet $(P<0 \cdot 05)$

Table 3. Serum fatty acid compositions ( $\mathrm{g} / 100 \mathrm{~g}$ total fatty acids) in rats fed low- or high-maize-oil (MO) diet or high-fish-oil (FO) diet ${ }^{*}$

(Mean values and standard deviations for five rats per group)

\begin{tabular}{|c|c|c|c|c|c|c|}
\hline \multirow[b]{2}{*}{ Fatty acids } & \multicolumn{2}{|c|}{ Low MO } & \multicolumn{2}{|c|}{ High MO } & \multicolumn{2}{|c|}{ High FO } \\
\hline & Mean & SD & Mean & SD & Mean & SD \\
\hline $14: 0$ & 0.67 & 0.26 & 0.35 & 0.21 & 0.72 & 0.34 \\
\hline $16: 0$ & $23 \cdot 18^{a}$ & $2 \cdot 76$ & $15 \cdot 73^{b}$ & 3.28 & $18 \cdot 81^{a b}$ & 3.89 \\
\hline $18: 0$ & 13.97 & 4.29 & 12.93 & 2.47 & 18.91 & 4.41 \\
\hline $18: 1$ & $19 \cdot 11^{a}$ & 4.07 & $12 \cdot 07^{b}$ & $1 \cdot 11$ & $10 \cdot 16^{b}$ & $2 \cdot 11$ \\
\hline $18: 2$ & $19 \cdot 50^{b}$ & $4 \cdot 20$ & $27 \cdot 35^{a}$ & 2.50 & $12 \cdot 50^{b}$ & $2 \cdot 50$ \\
\hline $20: 4$ & $22 \cdot 84^{b}$ & 3.62 & $30 \cdot 48^{a}$ & 6.58 & $11.44^{c}$ & $2 \cdot 28$ \\
\hline $20: 5$ & $0.05^{b}$ & 0.12 & $0.05^{b}$ & 0.08 & $14 \cdot 31^{a}$ & $2 \cdot 36$ \\
\hline $22: 6$ & $0.67^{b}$ & 0.31 & $0.97^{b}$ & 0.33 & $13 \cdot 15^{a}$ & 3.33 \\
\hline
\end{tabular}

\footnotetext{
a,b,c Mean values within a row with unlike superscript letters were significantly different: $P<0.05$.
}

* For details of diets and procedures, see Table 1 and p. 190
(Table 4). Higher hepatic SOD activity was also noted in rats fed FO than those fed the MO diets $(P<0 \cdot 001)$. In the high-FO group, rats administered $200 \mathrm{mg} \mathrm{GO} / \mathrm{kg}$ body weight had greater SOD activity than rats receiving the other doses of GO $(P<0 \cdot 05)$. In addition, there was an interaction between dietary fat and GO on the SOD activity in rat livers.

Dietary fat, but not GO, affected the $\alpha$-tocopherol content of rat liver. Rats fed the high-FO diet had a greater $\alpha$-tocopherol level than rats fed the high-MO diet $(P<0 \cdot 05)$. Hepatic GSH level was also noted to be affected by dietary fat but not by GO (Table 4 ). Rats fed the lowMO or high-FO diet had significantly greater hepatic GSH level than rats fed a high-MO diet $(P<0 \cdot 01)$. There was no effect of dietary fat or GO on GSH:GSSG ratio. The TBARS levels in the liver tissues, however, were significantly higher in rats fed FO than rats fed the MO diets $(P<0.001)$ (Table 4). In the low-MO group, rats administered $200 \mathrm{mg} \mathrm{GO} / \mathrm{kg}$ had lower TBARS production than rats receiving $0 \mathrm{mg} \mathrm{GO} / \mathrm{kg}(P<0.05)$.

In addition to the endogenous TBARS, the protection of GO on lipid peroxidation in rats fed the low-MO diet was also examined in the presence of exogenous oxidant (Fig. 2). With $50 \mu \mathrm{M}-\mathrm{FeSO}_{4}$ incubation, 3-fold higher TBARS levels were produced compared with conditions in which the oxidant was absent $(0.77 v .0 .20 \mathrm{nmol} / \mathrm{mg}$ protein). The increase of lipid peroxidation by $\mathrm{FeSO}_{4}$, however, was significantly suppressed in those prepared from rats given 80 and $200 \mathrm{mg} \mathrm{GO} / \mathrm{kg}$ body weight $(P<0 \cdot 05)$.

\section{Drug-metabolizing enzyme activities}

The results indicate that both dietary fat and GO significantly modulated EROD and NDMAD activities (Table 5). Rats fed the high-FO diet had significantly higher

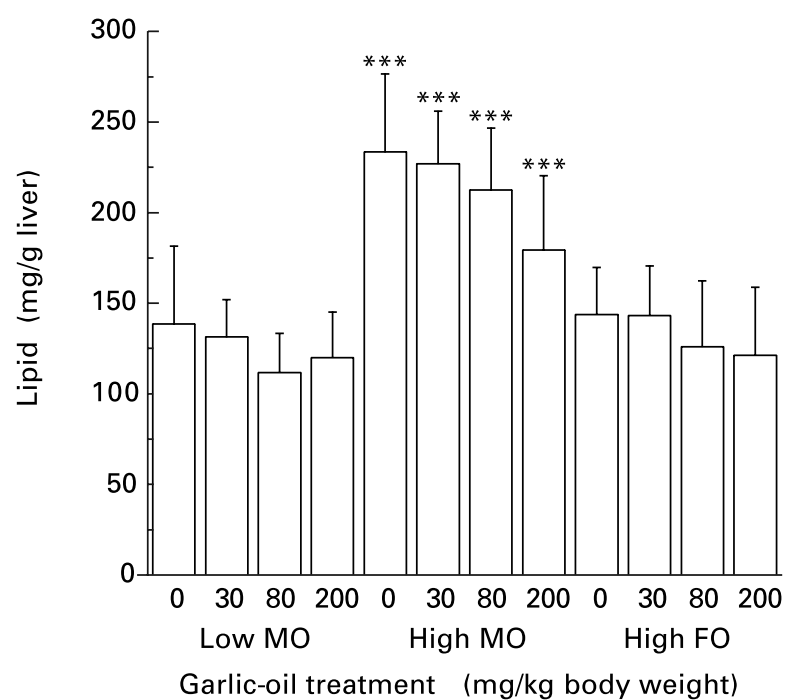

Fig. 1. Effect of dose of garlic oil $(0-200 \mathrm{mg} / \mathrm{kg}$ body weight three times per week) on the liver lipid concentration in rats fed a high maize-oil (MO) or high-fish oil (FO) diet for 6 weeks. For details of diets and procedures, see Table 1 and p. 192. Values are mean for five rats per group with standard deviations shown by vertical bars. Mean values were significantly greater than those for the low-MO and high-FO diets for each dose of garlic oil: ${ }^{\star \star \star} P<0.001$. 


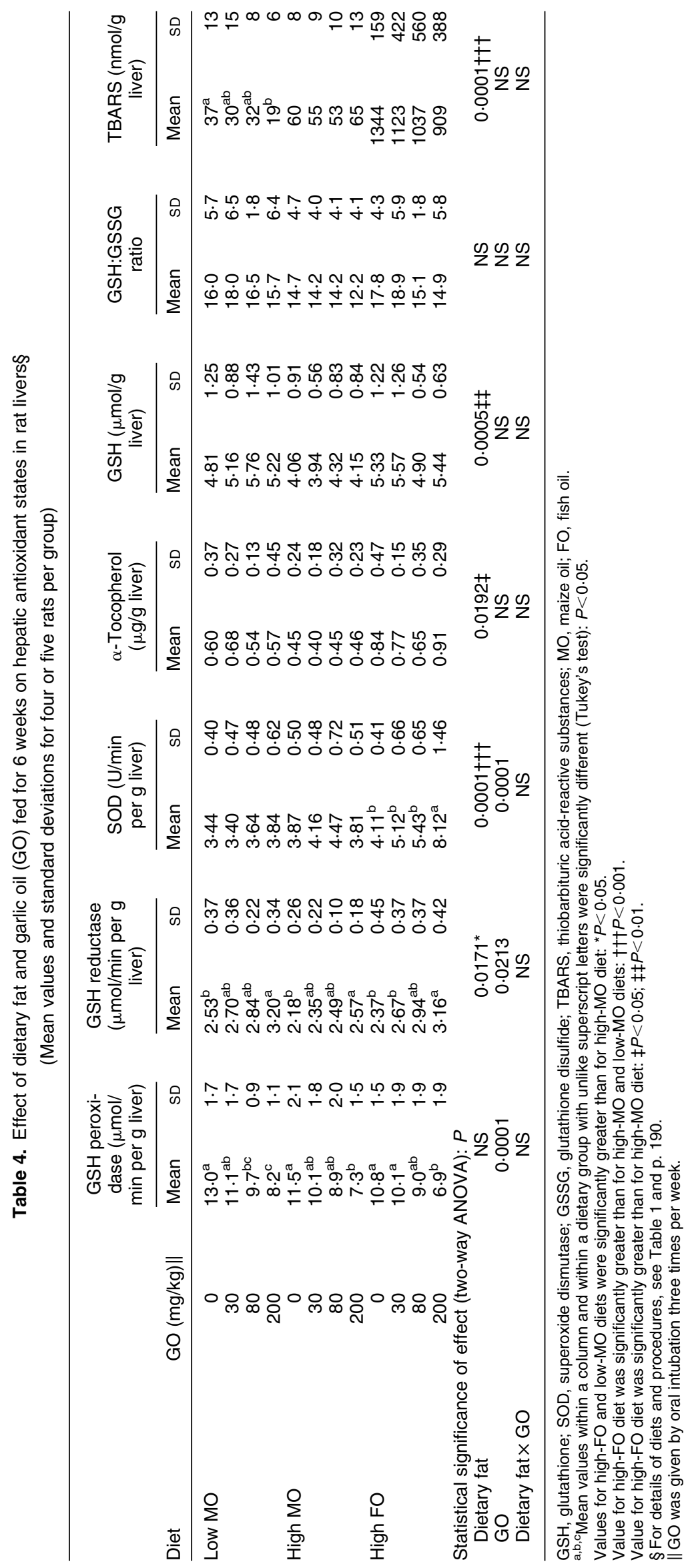




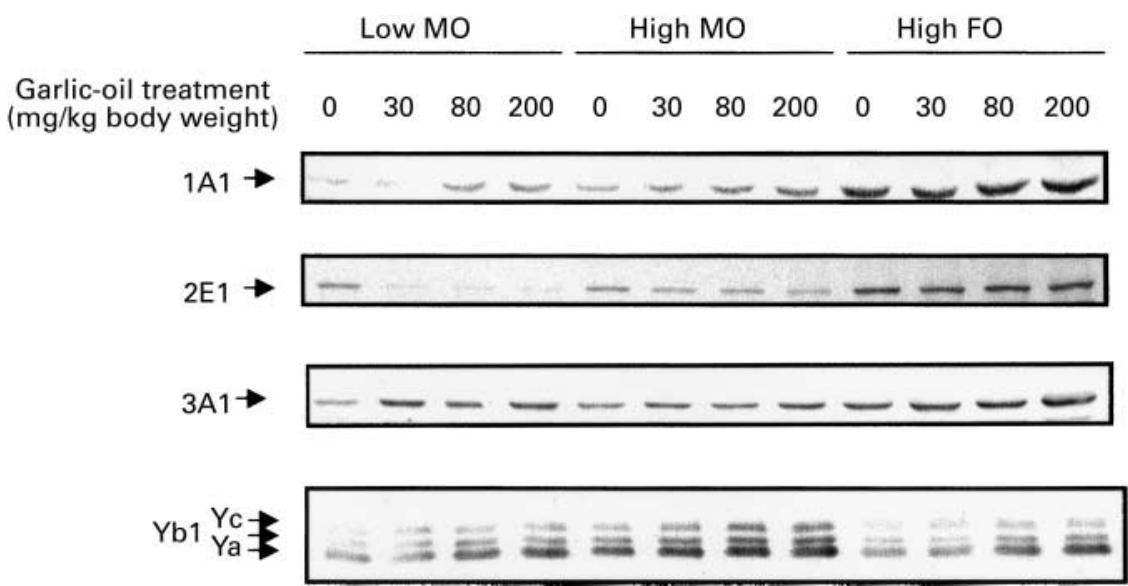

Fig. 3. Immunoblot analysis of hepatic cytochrome P450 (CYP) 1A1, CYP2E1, CYP3A1 and glutathione $S$-transferase isoenzymes $\mathrm{Ya}, \mathrm{Yb1}$ and $\mathrm{Yc}$. Microsomal and cytosolic proteins were pooled from five rats' livers per group. Each group of rats was fed a low-maize oil (MO), high-MO diet or a high-fish oil (FO) diet for 6 weeks. Proteins were electrophoretically separated on SDS-polyacrylamide gels and were transferred to polyvinylidiene difluoride membranes. Immunoreactive bands were stained with primary antibodies and the peroxidase-conjugated secondary antibody. Microsomal and cytosolic proteins of individual rats were tested in triplicate in each group and similar results were obtained. For details of diets and procedures, see Table 1 and p. 190.

was also noted that the combined changes of CYP1A1, CYP2E1 and CYP3A1 protein level by GO and FO are additive.

\section{mRNA expression}

Northern blots revealed that the changes of CYP1A1 and CYP3A1 mRNA levels (Fig. 4) were consistent with the protein levels stated previously. The transcripts of hepatic CYP1A1 and CYP3A1 were greater in rats fed the highFO diet than in those fed the low-MO or high-MO diet (Fig. 4(A)). The dose-dependent increase by GO treatment was found in all dietary groups. In addition, CYP1A1 and CYP3A1 mRNA levels were increased additively in rats fed the high-FO diet and receiving GO. The CYP1A1 transcripts of rats fed the low-MO, high-MO or high-FO diet and receiving $200 \mathrm{mg} \mathrm{GO} / \mathrm{kg}$ body weight were 5.7 (SD 1.4), 5.4 (SD 2.9) and 22.4 (SD 7.3)-fold (n 3) that of rats fed the low-MO diet without GO respectively; the CYP3A1 transcripts were 5.2 (SD 2.5), 4.9 (SD 1.4) and $14 \cdot 6$ (SD 2.7)-fold (n 3) respectively (Fig. 4(B)).

\section{Discussion}

In this 6-week experiment, with the exception of the relative spleen and jugular lymph-node weight, the bodyweight gain, relative heart and kidney weights were not affected by the dietary lipid and GO manipulation. Among three GSH-related enzymes studied, the activity of GSH peroxidase was affected only by GO, whereas the activity of GSH reductase (Table 4) and GST (Table 5) were significantly modulated by both GO and dietary fat. As shown, GO dose-dependently decreased GSH peroxidase activity, but the activities of GSH reductase and GST were dose-dependently increased. The decrease of
GSH peroxidase activity was consistent with our previous report (Sheen et al. 1999). Iqbal \& Athar (1998), however, reported that renal GSH peroxidase activity in rats pretreated with GO (50 and $100 \mathrm{mg} / \mathrm{kg}$ body weight) and then injected intraperitoneally with iron-nitrilotriacetate $(9 \mathrm{mg} /$ $\mathrm{kg}$ body weight) was significantly increased compared with rats without GO. It seemed that GO pre-treatment offers protection to rats against iron-nitrilotriacetateinduced nephrotoxicity. The discrepancy between these studies may be due to the target organ studied and the exposure of animals to toxin. Although GSH peroxidase activity was decreased by GO, the increase of GST activity, which acts as a Se-independent GSH peroxidase that reduces a variety of organic hydroperoxides to alcohols, may partly compensate for the loss of Se-dependent GSH peroxidase. In the study of Iqbal \& Athar (1998), they also found that GO pre-treatment significantly increased renal GSH reductase activity of rats exposed to iron-nitrilotriacetate compared with rats receiving no GO pre-treatment. Taken together, GO-suppressed $\mathrm{FeSO}_{4}{ }^{-}$ induced lipid peroxidation can be partly attributed to its modulation of GSH-related antioxidant enzyme activities (Fig. 2).

In addition to GO, FO increased the hepatic GSH reductase and GST activities. GSH reductase is responsible for the regeneration of GSH from oxidized GSH. A lower GSH reductase activity may partly explain the slightly lower GSH level and GSH:GSSG ratio noted in the highMO group (Table 4). In contrast, FO had no effect on GSH peroxidase in rat livers. FO enhanced intrinsic GSH peroxidase activity in human vascular endothelial cells and such an induction may be an important mechanism protecting cells against oxidative damage (Crosby et al. 1996). Although no change in GSH peroxidase activity was noted, FO-induced an increase in the activity of GST that can take over the role of GSH peroxidase, at least in 
(A)
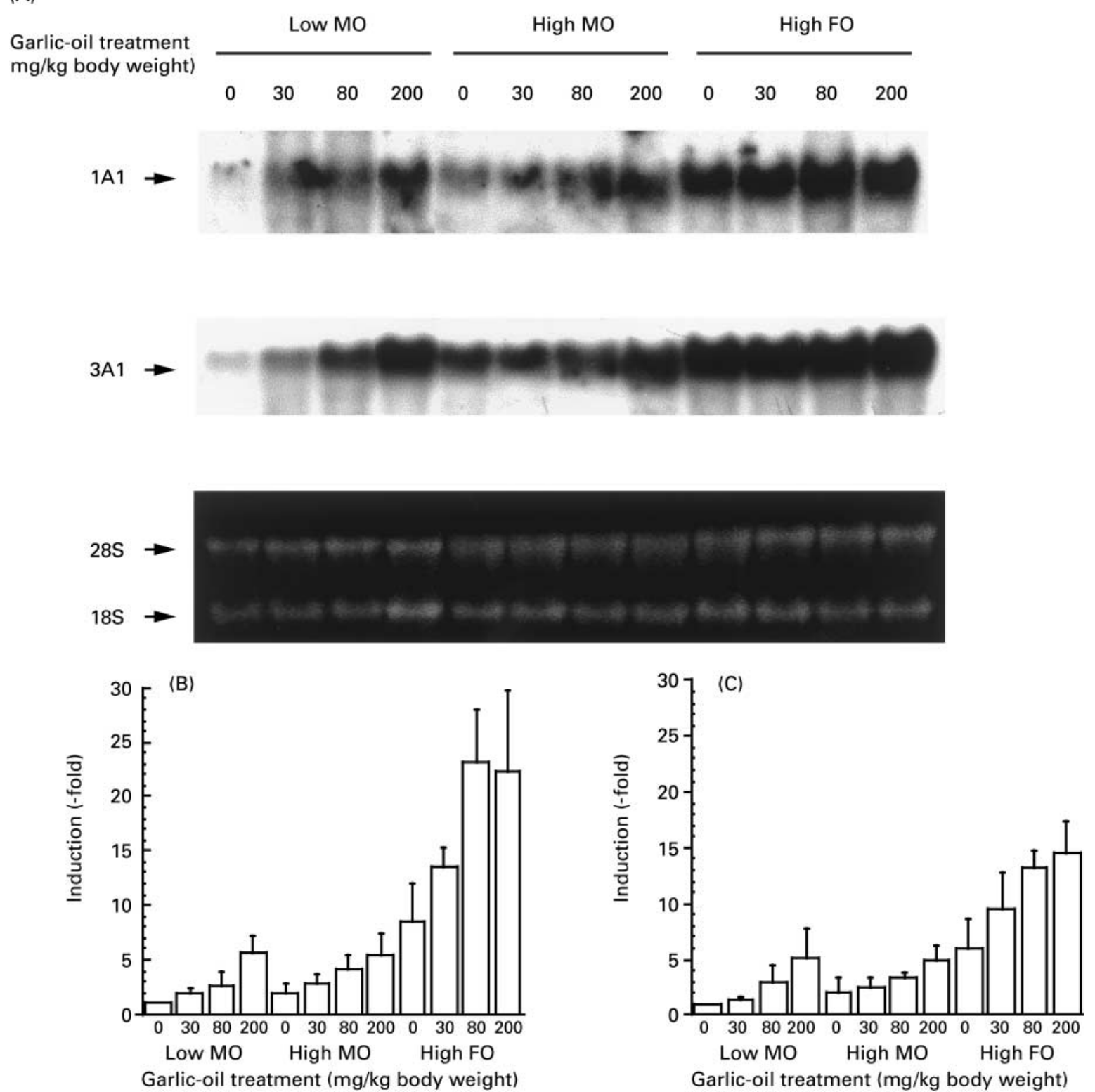

Fig. 4. Northerm blot analysis of hepatic cytochrome $P 450$ (CYP) $1 A 1$ and CYP $3 A 1$ levels in rats dosed with garlic oil $(0-200 \mathrm{mg} / \mathrm{kg}$ body weight three times per week) and fed a low-maize oil (MO), high MO or a high-fish oil (FO) diet for 6 weeks. Total RNA was extracted by Trizol. For details of diets and procedures, see Table 1 and p. 190. An equal amount of RNA was subjected to Northern blot analysis (20 ug per lane; (A)). The filter was first hybridized with a CYP3A1 CDNA and then rehybridized with a CYP1A1 cDNA after deprobing. The induction (-fold) of CYP1A1 (B) and CYP3A1 (C) mRNA was quantitated by densitometry based on the relative amount of 18S RNA.

part. The high content of polyunsaturated fatty acids in the FO increases lipid peroxidation and production of free radicals (Crosby et al. 1996; Ruiz-Gutiérrez et al. 1999). Induction of the activity of NDMAD and expression of CYP2E1 (Table 5), which is known to be involved in fatty acid oxidation and stimulate lipid peroxidation (Leclercq et al. 2000), also accelerated the endogenous oxidative stress in the high-FO-fed rats. As a consequence, there is growing concern that habitual intake of high quantities of FO may induce oxidative damage. However, the effectiveness of GO on the modulation of antioxidant enzyme activity and on the suppression of CYP2E1 expression suggests that the co- administration of GO may compensate for the risk of oxidative-related diseases.

Although both GO and dietary fat modulated GSHrelated enzyme activity, lack of interaction revealed that GO and dietary fat act independently. In contrast, GO interacted with dietary fat on the hepatic SOD activity. Rats fed FO not only had significantly greater SOD activity than rats fed the MO diets, but GO also synergistically enhanced the induction of FO on this enzyme activity. Venkatraman et al. (1994) and Fernandes et al. (1996) reported that the autoimmune-prone $\mathrm{NZB} \times \mathrm{NZW} \quad \mathrm{F}_{1}$ mice fed FO had significantly greater hepatic $\mathrm{Cu}, \mathrm{Zn}-\mathrm{SOD}$ activity than rats fed MO; they suggested that $n-3$ lipids 
delay the onset of autoimmune disease in $\mathrm{B} / \mathrm{W}$ mice, perhaps via the enhancement of hepatic antioxidant enzyme activities and expression and increase of programmed cell death to prevent accumulation of self-reactive immune cells in lymphoid organs.

The present study demonstrated that both GO and FO are two food components that modulate drug-metabolizing systems. The results showed that FO increased EROD and NDMAD activities compared with $\mathrm{MO}$, and high-fat diets increased GST activity (Table 5) compared with $50 \mathrm{~g} \mathrm{MO} /$ $\mathrm{kg}$ diet. Meanwhile, regardless of dietary fat, GO dosedependently increased GST and EROD and decreased NDMAD activities. Northern and Western blot results further demonstrated that the modulation by GO and dietary fat of CYP1A1, CYP2E1 and CYP3A1 and GST isoenzymes occur at the transcriptional and/or posttranscriptional stages. Moreover, the combined effects of GO and FO on CYP1A1, CYP2E1 and CYP3A1 protein and/or mRNA expression appeared to be additive. The combined effect of GO and FO on drug metabolism, obtained in the present study and in our previous study (Chen et al. 2001), demonstrated that the usefulness of co-administration of GO and FO is not only due to the decrease in blood cholesterol (Alder \& Holub, 1997; Morcos, 1997), but also to a modulation of drug metabolism. The modulation of drug-metabolizing enzymes by dietary components may also have a major impact on drug pharmacokinetics, drug-drug interactions, toxicity and carcinogenicity of foreign chemicals, and on the activity and disposition of endogenous compounds (Conney, 1982). In the present study, changes in drugmetabolizing enzyme activities were noted to be inconsistent with the CYP protein and mRNA levels, especially for erythromycin demethylase activity and CYP3A1 expression. This discrepancy is attributed, at least in part, to the lack of enzyme substrate specificity.

Steatosis of the liver is an important factor influencing hepatic drug-metabolizing enzyme activity and expression. In two rat models of non-alcoholic steatohepatitis and microvesicular steatohepatitis that were induced by refeeding a high-glucose, fat-free diet following $48 \mathrm{~h}$ fasting and orotic acid respectively, CYP2E1, CYP3A and CYP2A protein level and activity were shown to be inversely correlated with the degree of hepatic fat content (Leclercq et al. 1998; Su et al. 1999). This suggests that lipid deposition in the liver can change the drug metabolism. However, in a mouse non-alcoholic steatohepatitis model produced by the intake of methionine- and cholinedeficient diet, CYP2E1 induction accompanied steatosis (Leclercq et al. 2000). This controversy indicates that the relationship between liver fat deposition and drug-metabolizing enzyme expression is more complex and may not be simply attributed to the fat content. In the present study, rats fed the high-MO diet had $70 \%$ higher liver lipid content than those fed the low-MO diet, but no changes in CYP1A1, CYP2E1 and CYP3A1 proteins and mRNA levels were noted. Further study is required to clarify the effect of diet-induced hepatosteatosis on the drug metabolism.

Although dietary lipids were once thought to modulate microsomal drug-metabolizing enzymes by changing the lipid environment of the microsomal membrane matrix, it is now known that the mechanisms of this modulation are more complex. Numerous studies have suggested that dietary fatty acids can directly and indirectly modulate receptor-mediated signalling pathways at multiple levels and therefore the gene expression (Hwang \& Rhee, 1999). One well-known example is that the gene products involved in lipid metabolism, such as acyl-CoA oxidase, fatty acid synthase and CYP4A, are regulated by certain polyunsaturated fatty acids and their metabolites through the peroxisome proliferator-activated receptor (Jump, 2002), a member of nuclear receptor 1 gene family. Pregnane $\mathrm{X}$ receptor and constitutive androstane receptor are two members of the nuclear receptor 1 family, and are known to participate in the induction of CYP3A and CYP2B expression respectively, in the presence of a broad range of drugs and steroids (Waxman, 1999). Although there is no evidence that indicates that fatty acids are capable of binding to pregnane $X$ receptor and constitutive androstane receptor, it is clear that CYP3A1 and CYP2B1are up-regulated in rats fed FO (Chen et al. 2001). The existence of undiscovered receptor-mediated pathways cannot be excluded. Moreover, $\alpha$-tocopherol modulation on the drug-metabolizing enzyme activity and expression is an alternative explanation. Recently, we demonstrated that $\alpha$-tocopherol up-regulates CYP2B1 expression via prostaglandin $\mathrm{E}_{2}$-mediated pathways (Tsai et al. 2001). Such an effect may explain in part the higher CYP protein and mRNA content in the high-FO group, which had a greater $\alpha$-tocopherol level than the MO-fed groups. GST and many CYP enzymes have been shown to be inducible in the presence of various drugs and food components (Vos \& Van Bladeren, 1990; Guengerich, 1995). The molecular mechanisms involved in the regulation of GST isoenzyme genes are mediated by an antioxidant-responsive element and the activator protein1-responsive element; both are located on GST gene promoter and/or enhancer regions (Rushmore \& Pickett, 1990; Bergelson et al. 1994; Fotouhi-Ardakani \& Batist, 1999). However, the molecular mechanism of garlic's effect is not clear and it is compelling to investigate whether GO mediates GST genes through the antioxidant-responsive element pathway and/or the Fos/Jun binding to AP-1 binding site. Elucidating the molecular and cellular mechanisms of such responses obtained in the present study requires further study. In conclusion, in addition to the well-known functions of GO and FO, the effect of these two popular health supplements on disease prevention may be due to their regulation of antioxidant- and drug-metabolizing enzyme activity and expression. The combined effect of GO and FO on drug-metabolizing enzymes is additive.

\section{Acknowledgements}

This research was supported by the Department of Health, Republic of China, Grant DOH 91-TD-1010. Our thanks also go to Dr Suzanne Hendrich, Department of Food Science and Human Nutrition, Iowa State University, for critically reading this manuscript and for stimulating discussions. 


\section{References}

Agarwal KC (1996) Therapeutic actions of garlic constituents. Medicinal Research Review 16, 111-124.

Alder AJ \& Holub BJ (1997) Effect of garlic-oil and fish-oil supplementation on serum lipid and lipoprotein concentrations in hypercholesterolemic men. American Journal of Clinical Nutrition 65, 445-450.

Bang HO, Dyerberg J \& Sinclair HM (1980) The composition of the Eskimo food in north western Greenland. American Journal of Clinical Nutrition 33, 2657-2661.

Bellomo G, Mirabelli F, DiMonte D, Richelmi P, Thor H, Orrenius C \& Orrenius S (1987) Formation and reduction of glutathione-mixed disulfides during oxidative stress. Biochemical Pharmacology 36, 1313-1320.

Bergelson S, Pinkus R \& Daniel V (1994) Induction of AP-1 (Fos/Jun) by chemical agents mediates activation of glutathione S-transferase and quinone reductase gene expression. Oncogene 9, 565-571

Catignani GL \& Bieri JG (1983) Simultaneous determination of retinol and alpha-tocopherol in serum or plasma by liquid chromatography. Clinical Chemistry 29, 708-712.

Chen HW, Yang JJ, Tsai CW, Wu JJ, Sheen LY, Ou CC \& Lii CK (2001) Dietary fat and garlic oil independently regulate hepatic cytochrome P450 2B1 and the placental form of glutathione S-transferase expression in rats. Journal of Nutrition 131, $1438-1443$

Conney AH (1982) Induction of microsomal enzymes by foreign chemicals and carcinogenesis by polycyclic aromatic hydrocarbons: G. H. A. Clowes memorial lecture. Cancer Research 42, 4875-4917.

Crosby AJ, Wahle KW \& Duthie GG (1996) Modulation of glutathione peroxidase activity in human vascular endothelial cells by fatty acids and the cytokine interleukin-1 beta. Biochimica et Biophysica Acta 1303, 187-192.

Cross CE, Halliwell B, Borish ET, Pryon WA, Ames BN, Saul RL, McCord JM \& Harman D (1987) Oxygen radicals and human disease. Annals of Internal Medicine 107, 526-545.

Dyerberg J, Bang HO \& Hjørne N (1975) Fatty acid composition of the plasma lipids in Greenland Eskimos. American Journal of Clinical Nutrition 28, 958-966.

Fang JL, Vaca CE, Valsta LM \& Mutanen M (1996) Determination of DNA adducts of malondialdehyde in humans: effects of dietary fatty acids consumption. Carcinogenesis 17, $1035-1040$

Fernandes G, Chandrasekar B, Luan X \& Troyer DA (1996) Modulation of antioxidant enzymes and programmed cell death by n-3 fatty acids. Lipids 31, S91-S96.

Fleischhauer AT \& Arab L (2001) Garlic and cancer: a critical review of the epidemiologic literature. Journal of Nutrition 131, 1032S-1040S.

Folch J, Lees M \& Sloane-Stanley GH (1957) A simple method for the isolation and purification of total lipides from animal tissues. Journal of Biological Chemistry 226, 497-509.

Fotouhi-Ardakani N \& Batist G (1999) Genomic cloning and characterization of the rat glutathione S-transferase-A3-subunit gene. Biochemical Journal 339, 685-693.

Fox PL \& DiCorleto PE (1988) Fish oil inhibits endothelial cell production of platelet-derived growth factor-like protein. Science 241, 453-456.

Fraga CG, Leibovitz BE \& Tappel AL (1988) Lipid peroxidation measured as thiobarbituric acid-reactive substances in tissue slices: characterization and comparison with homogenates and microsomes. Free Radical Biology and Medicine 4, $155-161$.

Goodnight SH Jr, Harris WS, Connor WE \& Illingworth DR
(1982) Polyunsaturated fatty acids, hyperlipidemia and thrombosis. Arteriosclerosis 2, 87-113.

Guengerich FP (1991) Oxidation of toxic and carcinogenic chemicals by human cytochrome P-450 enzymes. Chemical Research in Toxicology 4, 391-407.

Guengerich FP (1995) Influence of nutrients and other dietary materials on the cytochrome P-450 enzymes. American Journal of Clinical Nutrition 61, 651S-658S.

Habig WH, Pabst MJ \& Jakoby WB (1974) Glutathione S-transferase. The first enzymatic step in mercapturic acid formation. Journal of Biological Chemistry 249, 7130-7139.

Hwang D \& Rhee SH (1999) Receptor-mediated signaling pathways: potential targets of modulation by dietary fatty acids. American Journal of Clinical Nutrtion 70, 545-556.

Iqbal M \& Athar M (1998) Attenuation of iron-nitrilotriacetate (Fe-NTA)-mediated renal oxidative stress, toxicity and hyperproliferative response by the prophylactic treatment of rats with garlic oil. Food and Chemical Toxicology 36, 485-495.

Jump DB (2002) Dietary polyunsaturated fatty acids and regulation of gene expression. Current Opinion in Lipidology 13, $155-164$.

Laemmli UK (1970) Cleavage of structural proteins during the assembly of the head of bacteriophage T4. Nature 277, 680-685.

Lawrence RA \& Burk RF (1976) Glutathione peroxidase activity in selenium-deficient rat liver. Biochemical and Biophysics Research Communication 71, 952-958.

Leclercq I, Horsmans Y, Desager JP, Delzenne N \& Geubel AP (1998) Reduction in hepatic cytochrome P-450 is correlated to the degree of liver fat content in animal models of steatosis in the absence of inflammation. Journal of Hepatology 28, $410-416$.

Leclercq IA, Farrell GC, Field J, Bell DR, Gonzalez FJ \& Robertson GR (2000) CYP 2E1 and CYP 4A as microsomal catalysts of lipid peroxides in murine nonalcoholic steatohepatitis. Journal of Clinical Investigation 105, 1067-1075.

Lepage G \& Roy CC (1986) Direct transesterification of all classes of lipids in one-step reaction. Journal of Lipid Research 27, 114-120.

Lowry OH, Rosebrough NJ, Farr AL \& Randall RJ (1951) Protein measurement with Folin phenol reagent. Journal of Biological Chemistry 193, 265-275.

Machlin ZJ \& Bendich A (1987) Free radical tissue damage: protective role for antioxidant nutrients. FASEB Journal 1, 441-445.

Morcos NC (1997) Modulation of lipid profile by fish oil and garlic combination. Journal of the National Medical Association 89, 673-678.

Nash T (1953) The colorimetric estimation of formaldehyde by means of the Hantzsch reaction. Biochemical Journal 55, 416-421.

National Research Council (1985) Guide for the Care and Use of Laboratory Animals. Publication no. 85-23 (rev.). Bethesda, MD: National Institutes of Health.

Phelps S \& Harris WS (1993) Garlic supplementation and lipoprotein oxidation susceptibility. Lipids 28, 475-477.

Poul RJ \& Fouts JR (1980) A rapid method for assaying the metabolism of 7-ethoxyresorufin subcellular fractions. Analytical Biochemistry 107, 150-155.

Rahman K (2001) Historical perspective on garlic and cardiovascular disease. Journal of Nutrition 313, 977S-979S.

Reddy BS \& Sugie S (1988) Effect of different levels of omega-3 and omega- 6 fatty acids on azoxymethane-induced colon carcinogenesis in F344 rats. Cancer Research 48, 6642-6647.

Reed DJ, Babson JR, Beatty PW, Brodie AE, Ellis WW \& Potter DW (1980) High-performance liquid chromatography analysis of nanomole levels of glutathione, glutathione disulfide, and 
related thiols and disulfides. Analytical Biochemistry 106, $55-62$.

Ruiz-Gutiérrez V, Pérez-Espinosa A, Vázquez CM \& SantaMaría C (1999) Effects of dietary fats (fish, olive and higholeic-acid sunflower oils) on lipid composition and antioxidant enzymes in rat liver. British Journal of Nutrition 82, 233-241.

Rushmore TH \& Pickett CB (1990) Transcriptional regulation of the rat glutathione S-transferase Ya subunit gene. Journal of Biological Chemistry 165, 14648-14653.

Sheen LY, Chen HW, Kung YL, Liu CT \& Lii CK (1999) Effects of garlic oil and its organosulfur compounds on the activities of hepatic drug-metabolizing and antioxidant enzymes in rats fed high- and low-fat diets. Nutrition and Cancer 35, 160-166.

Shimokawa H \& Vanhoutte PM (1989) Dietary omega-3 fatty acids and endothelium-dependent relaxations in porcine coronary arteries. American Journal of Physiology 256, H968-H973.

Sparnins VL, Barany G \& Wattenberg LW (1988) Effects of organosulfur compounds from garlic and onions on benzo[a]pyrene-induced neoplasia and glutathione S-transferase activity in the mouse. Carcinogenesis 9, 131-134.

Su GM, Sefton RM \& Murray M (1999) Down-regulation of rat hepatic microsomal P-450 in microvesicular steatosis induced by orotic acid. Journal of Pharmacology and Experimental Therapeutics 291, 953-959.

Tsai CF, Lii CK, Yang JJ, Liu K, Lin WL \& Chen HW (2001) Prostaglandin E2 is involved in the increase of cytochrome P-450 2B1 expression by alpha-tocopheryl succinate in primary rat hepatocytes in the presence of phenobarbital. Nutrition and Cancer 41, 188-195.

Venkatraman JT, Chandrasekar B, Kim JD \& Fernandes G (1994) Effects of $n-3$ and $n-6$ fatty acids on the activities and expression of hepatic antioxidant enzymes in autoimmuneprone NZB $\times$ NZW F $F_{1}$ mice. Lipids 29, 561-568.

Vos RM \& Van Bladeren PJ (1990) Glutathione $S$-transferases in relation to their role in the biotransformation of xenobiotics. Chemico-Biological Interactions 75, 241-265.

Waxman DJ (1999) P450 gene induction by structurally diverse xenochemicals: central role of nuclear receptors CAR, PXR, and PPAR. Archives of Biochemistry and Biophysics 369, $11-23$.

Yang CS, Smith TJ \& Hong JY (1994) Cytochrome P-450 enzymes as targets for chemoprevention against chemical carcinogenesis and toxicity: opportunities and limitations. Cancer Research 54, 1982s-1986s. 